\title{
Redox-Responsive Polymeric RNAi Based on Multivalent Conjugation of siRNA for Improved Intracellular Delivery
}

Qiufang Bai ${ }^{a}$, Jun Liü,c, Jianan Tang ${ }^{c}$, Zhen Lid ${ }^{d^{*}}$ Xiujue Zheng ${ }^{b}$ and Qixian Chen ${ }^{c, e^{*}}$

${ }^{a}$ Department of Pharmacy, Affiliated Zhongshan Hospital of Dalian University, Dalian 116001, China.

${ }^{b}$ Department of Neurosurgery, First Affiliated Hospital, School of Medicine, Zhejiang University, Hangzhou 310003, China.

'Ningbo Hygeia Medical Technology Co., Ltd., No. 6 Jinyuan Road, Hing-Tech Zone, Ningbo 315201, China.

${ }^{\mathrm{d} C o l l e g e ~ o f ~ P h a r m a c y, ~ D a l i a n ~ M e d i c a l ~ U n i v e r s i t y, ~ N o . ~} 9$ West Section Lvshun South Road, Dalian 116044 China. Email: lizhenpharm@126.com

eSchool of Bioengineering, Dalian University of Technology, No. 2 Linggong Road, Dalian 116024, China. Email: qixian@dlut.edu.cn 


\section{Materials}

$\alpha$-Methoxy- $\omega$-amino-PEG (PEG) ( $\left.M_{\mathrm{w}}: 12 \mathrm{kDa}\right)$ and $\alpha$-acetal- $\omega$-amino-PEG (acetal-PEG) ( $M_{\mathrm{w}}: 12$ kDa) were purchased from SinoPEG Co. (Xiamen, China). N6-trifluoroacetyl-L-lysine Ncarboxyanhydride [Lys(TFA)-NCA] was purchased from Carbosynth Limited (Berkshire, UK). Cyclo[RGDfK(C-e-Acp)] (cRGD) peptide ( $\varepsilon$-Acp: 6-aminocaproic acid) was purchased from Synpeptide Co. Ltd. (Shanghai, China). N-succinimidyl 3-(2-pyridyldithio)-propionate (SPDP) and slide-a-lyzer dialysis cassettes $(\mathrm{MWCO}=10 \mathrm{kDa})$ were purchased from Thermo Scientific (Rockford, IL). siRNA possessing the following sequences are used: (1) Firefly GL3 luciferase (siluc): 5'-thiol-CUU ACG CUG AGU ACU UCG AdTdT-3' (sense), 5'-UCG AAG UAC UCA GCG UAA GdTdT-3' (antisense); (2) control (siContol): 5'-thiol-UUC UCC GAA CGU GUC ACG UdTdT3' (sense), 5'-ACG UGA CAC GUU CGG AGA AdTdT-30'(antisense). All fluorescence dyes (Cy5 and Су3) were attached to $3^{\prime}$-end of anti-sense stand of siluc, which was only used for fluorescence studies. (Madison, WI) according to the manufacturer's protocol. Dulbecco's modified eagle's medium (DMEM) and Dulbecco's phosphate-buffered saline (DPBS) were purchased from Sigma-Aldrich Co. (Madison, WI). Fetal bovine serum (FBS) was purchased from Dainippon Sumitomo Parma Co., Ltd. (Osaka, Japan). Cell culture lysis buffer and Luciferase Assay System Kit were purchased from Sigma Aldrich China (Shanghai, China). U87Luc cells [U-87 MG $\left(\right.$ ATCC $^{\circledR}$ HTB-14 $^{\mathrm{TM}}$ )] were obtained from the American Type Culture Collection (ATCC, Manassas, VA).

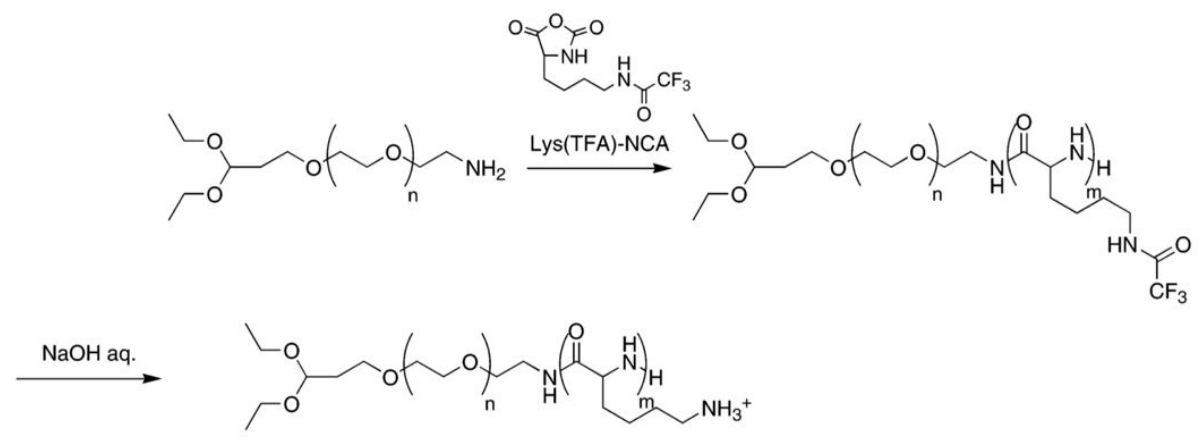




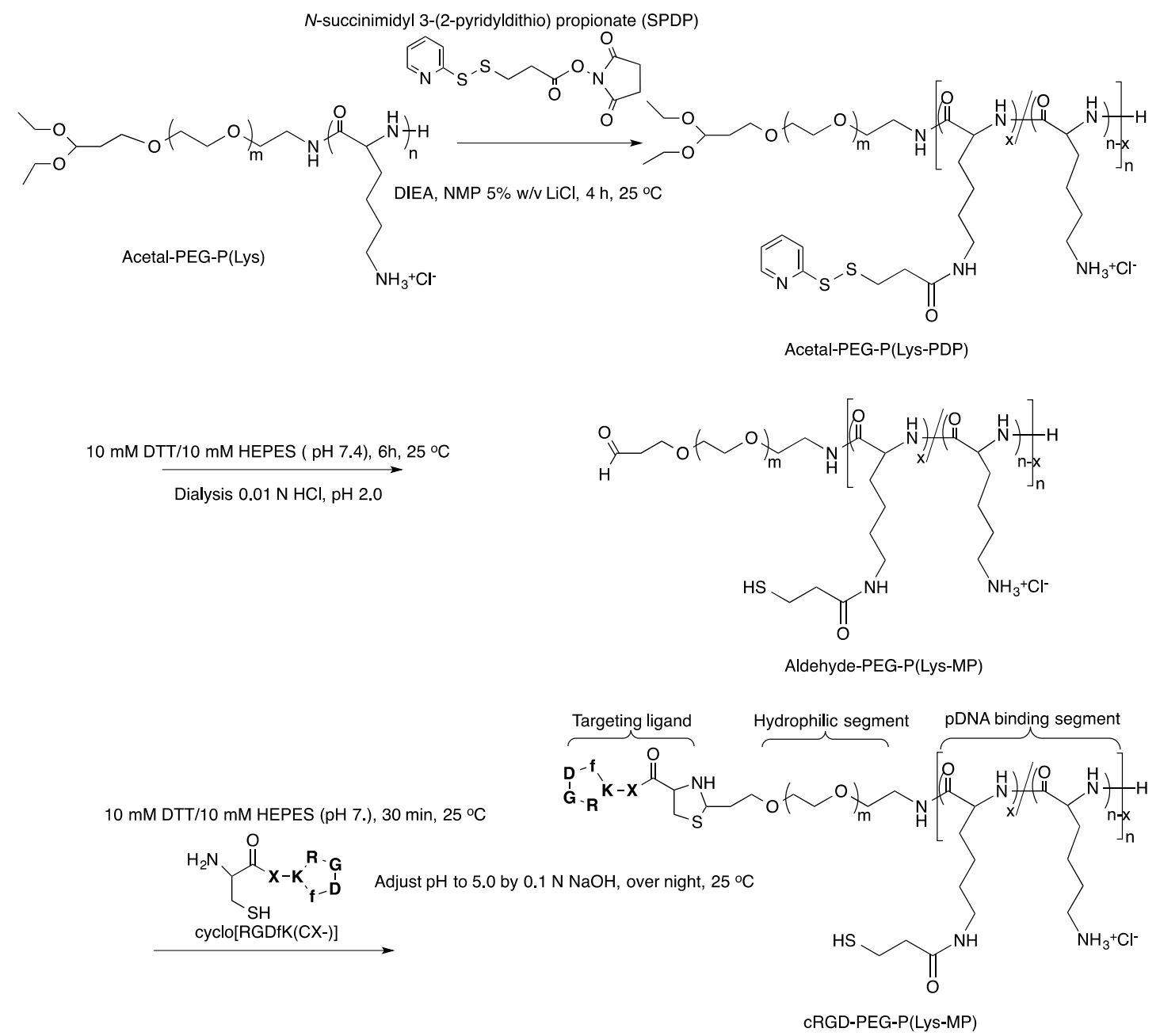

Scheme S1 Synthetic route in synthesis of cRGD-PEG-PLys(thiol)

\section{Synthesis of PEG-PLys}

Block copolymer of PEG-PLys was synthesized according to a ring-opening polymerization approach according to the previous report ${ }^{\mathrm{S1}}$. In brief, monomer of Lys(TFA)-NCA was polymerized from initiation of the $\omega$ - $\mathrm{NH}_{2}$ terminal group of methoxy (MeO)-PEG in $\mathrm{N}, \mathrm{N}$ dimethylformamide (DMF). The molecular weight distribution $\left(M_{w} / M_{n}\right)$ of the yielded PEGPLys(TFA) was determined to be 1.05 from gel permeation chromatography (GPC) equipped with TOSOH HLC-8220 calibrated based on varying $M_{\mathrm{w}}$ of commercial PEG standards. Furthermore, MeO-PEG-PLys(TFA) was dissolved in methanol containing $1 \mathrm{~N} \mathrm{NaOH}$ with the aim of remove protective TFA groups at $30^{\circ} \mathrm{C}$ for overnight reaction. 


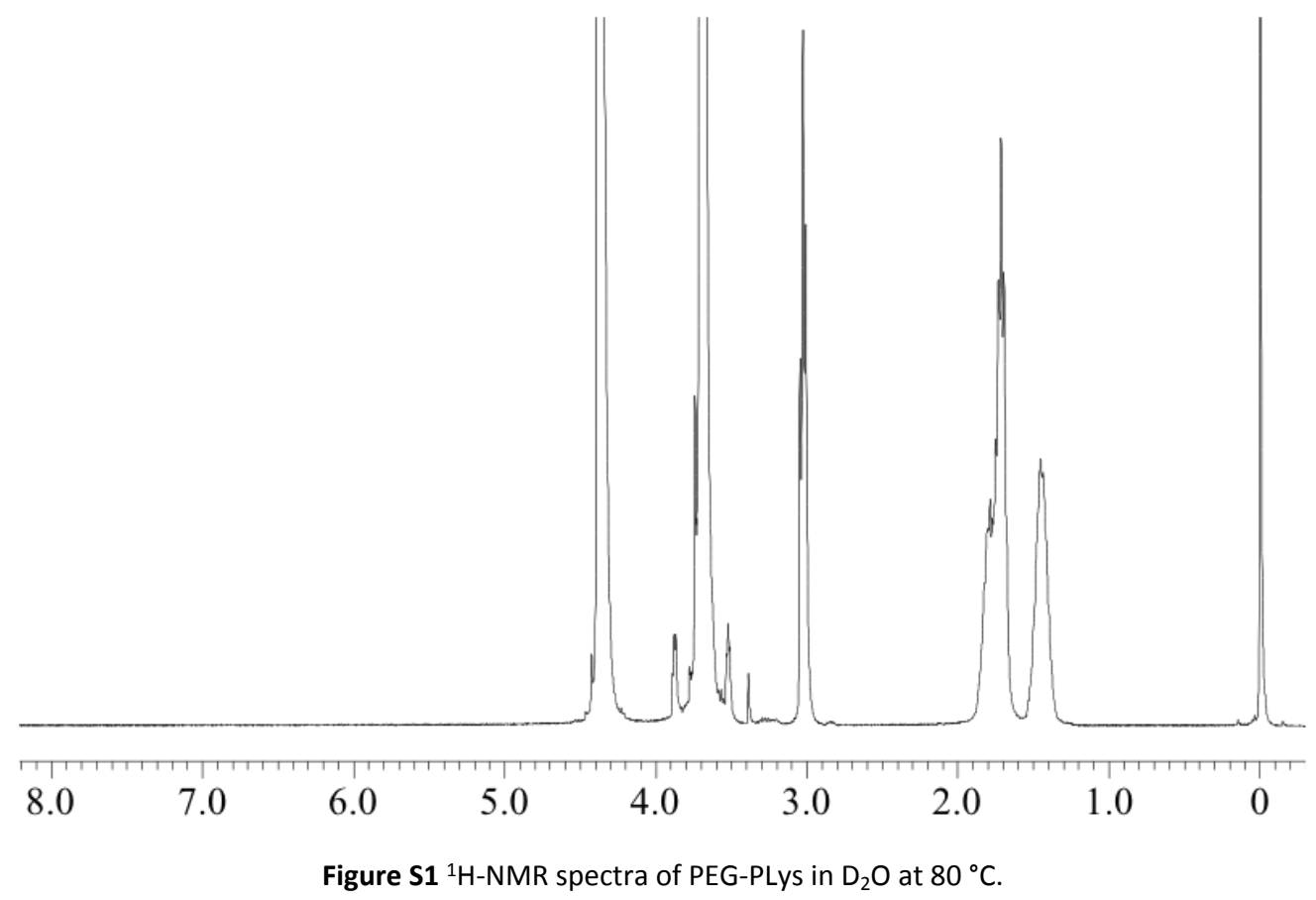

\section{Synthesis of acetal-PEG-PLys}

Following a similar synthetic procedure, acetal-PEG-PLys was also synthesized ${ }^{\mathrm{S2}}$.

\section{Synthesis of thiolated PEG-PLys [PEG-PLys(thiol]}

Thiolated PEG-PLys(thiol) were prepared by introducing pyridyldithiopropionyl (PDP) groups into the side chain of lysine units of the PLys segment of PEG-PLys using the heterobifunctional reagent $\mathrm{N}$-succinimidyl 3-(2-pyridyldithio) propionate (SPDP) ${ }^{\mathrm{S2}}$. In brief, PEG-PLys was dissolved in $\mathrm{N}$-methyl-2-pyrrolidone (NMP) supplemented with $5 \mathrm{wt} \% \mathrm{LiCl}$ and reacted with predefined concentration of SPDP pre-dissolved in NMP containing $N, N$ diisopropylethylamine (10 mol excess against SPDP) at room temperature. After $4 \mathrm{~h}$ reaction, the crude product was purified by precipitation into diethyl ether. Furthermore, the precipitated product was dissolved in $0.01 \mathrm{~N} \mathrm{HCl}$, dialyzed against the distilled water, and lyophilized to obtain PEG-PLys(PDP).

\section{Synthesis of thiolated acetal-PEG-PLys [acetal-PEG-PLys(thiol)]}

Block polymer acetal-PEG-PLys(thiol) was synthesized according to a similar synthetic procedure, which was further used for CRGD ligand conjugation ${ }^{\mathrm{s2}}$. 


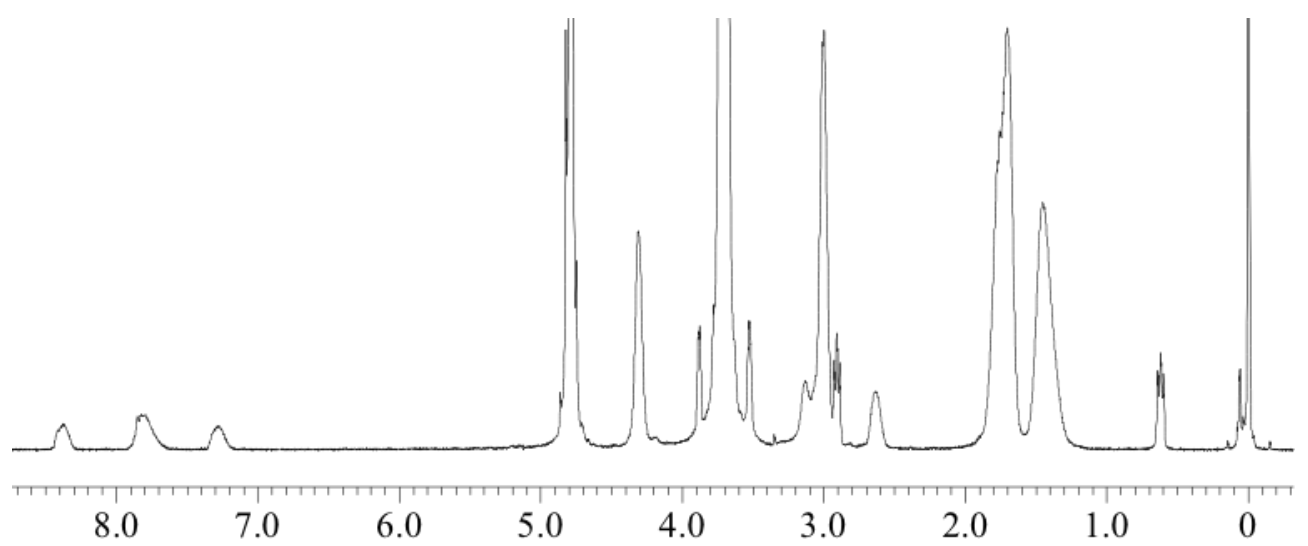

Figure S2 ${ }^{1} \mathrm{H}-\mathrm{NMR}$ spectra of acetal PEG-PLys(PDP) in $\mathrm{D}_{2} \mathrm{O}$ at $80^{\circ} \mathrm{C}$.

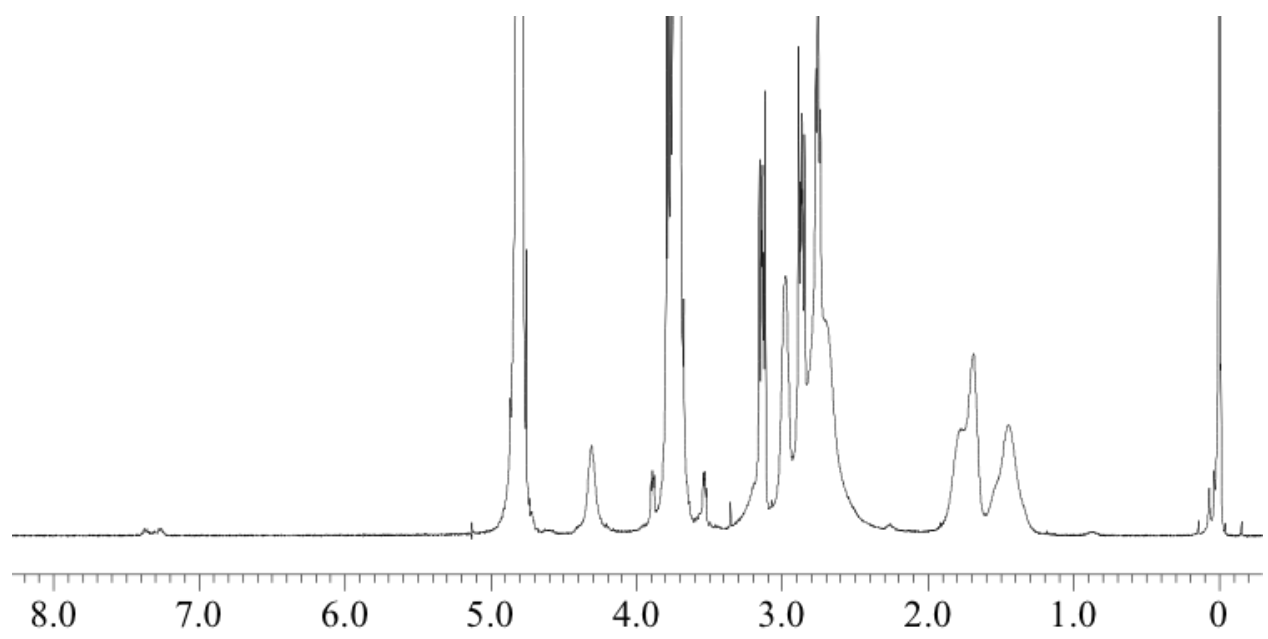

Figure $\mathbf{S 3}{ }^{1} \mathrm{H}$-NMR spectra of cRGD-PEG-PLys(PDP) in $\mathrm{D}_{2} \mathrm{O}$ at $80^{\circ} \mathrm{C}$.

\section{Synthesis of CRGD-PEG-PLys(thiol)}

The cyclo[RGDfK(C-ع-Acp)] (cRGD) peptide ligand was attached onto the $\alpha$-terminal of acetalPEG-PLys(thiol) through formation of a thiazolidine ring between the $\mathrm{N}$-terminal cysteine of the CRGD peptide and the aldehyde group from acetal-PEG-PLys following incubation at acidic $\mathrm{pH}(\mathrm{pH}=2)^{\mathrm{s} 2}$. In brief, acetal-PEG-PLys(thiol) was dissolved in $10 \mathrm{mM}$ HEPES buffer ( $\mathrm{pH}$ 7.4) and dialyzed against $0.01 \mathrm{~N} \mathrm{HCl}(\mathrm{pH} 2.0)$ to yield aldehyde from the acetal group. The $\mathrm{pH}$ of the dialyzed solution was adjusted to 2 by $0.01 \mathrm{~N} \mathrm{NaOH}$, following which the pre-DTT-treated CRGD solution was added dropwise while stirring. After stirring overnight at $25^{\circ} \mathrm{C}$, the polymer solution was dialyzed against HEPES with $150 \mathrm{mM} \mathrm{NaCl}$, followed by distilled water. Eventually, the solution was collected and lyophilized to obtain cRGD-PEG-PLys(thiol). The 
percentage of $C R G D$ conjugation was determined by the peak intensity ratio of benzyl protons (D-Phenyl alanine, f: D-Phe; $\delta=7.3-7.4 \mathrm{ppm}$ ) of the cRGD peptide to the methylene protons of PEG $(\delta=3.7 \mathrm{ppm})$ from the ${ }^{1} \mathrm{H}-\mathrm{NMR}$ spectra, and the conjugation ratio of cRGD was calculated to be $95 \%$.

\section{Synthesis of cRGD-PEG-PLys(siRNA)}

The yielded cRGD-PEG-PLys(thiol) $(0.1 \mu \mathrm{M})$ and siRNA $(2 \mu \mathrm{M})$ were mixed in PBS (10 mM, pH 7.4) containing $50 \mathrm{mM}$ DTT and incubated for $2 \mathrm{~h}$ at $4{ }^{\circ} \mathrm{C}$. Note that the number of the thiols from CRGD-PEG-PLys(thiol) was approximate 3-fold of the number of the thiols from siRNA. The above solution was transferred into dialysis bag (MWCO: $10 \mathrm{kDa}$ ) and subjected to dialysis 2 times against DMSO $(0.1 \mathrm{mM})$-containing ultrapure water and 3 times against ultrapure water. The dialysate was concentrated through ultrafiltration (MWCO: $30 \mathrm{kDa}$ ) for subsequent physiochemical or biological measurements. The conjugation efficiency of siRNA to CRGDPEG-PLys(thiol) was conducted under ICP-MS measurement based on phosphate from siRNA and sulfur from siRNA and cRGD-PEG-PLys(thiol) (ICP-MS-2030, Shimadazu Co., Kyoto, Japan).

\section{Gel Permeation Chromatography (GPC)}

The stock solution of cRGD-PEG-PLys(siRNA) was dissolved in PBS $(10 \mathrm{mM}, \mathrm{pH} 7.4)$ at a concentration of $1 \mathrm{mg} / \mathrm{mL}$, which was subsequently resorted into two equal fractions, either supplemented with GSH-containing PBS solution or blank PBS solution to have the final GSH concentration of $10 \mathrm{mM}$ or $0 \mathrm{mM}$ and final polymer concentration of $0.5 \mathrm{mg} / \mathrm{mL}$. The reaction solution was conducted for $2 \mathrm{~h}$ and transferred for aqueous GPC measurement. Note that the eluent carrier was PBS $(10 \mathrm{mM}, \mathrm{pH}$ 7.4) containing $250 \mathrm{mM} \mathrm{NaCl}$, which have the GSH concentration of either $10 \mathrm{mM}$ or $0 \mathrm{mM}$ in consistent with the sample solution.

\section{Polyacrylamide gel electrophoresis (PAGE) analysis}

The stock solution of cRGD-PEG-PLys(siRNA) was dissolved in PBS (10 mM, pH 7.4) at a concentration of $1 \mathrm{mg} / \mathrm{mL}$, which was subsequently resorted into two equal fractions, either supplemented with DTT-containing PBS solution or blank PBS solution to have the final GSH concentration of $10 \mathrm{mM}$ or $0 \mathrm{mM}$ and final polymer concentration of $0.5 \mathrm{mg} / \mathrm{mL}$. The reaction 
solution was conducted for $2 \mathrm{~h}$ and transferred for PAGE analysis at $100 \mathrm{~V}$ for $30 \mathrm{~min}$. Note that siRNA was stained by SyBr Green II for visualization.

\section{Dynamic light scattering (DLS)}

The hydrodynamic diameter and polydispersity index (PDI) of polymeric formulations were measured by DLS using a Zetasizer Nanoseries instrument (Malvern Instruments Ltd., UK). The measurement was performed 4 times at a detection angle of $173^{\circ}$ and a temperature of $25^{\circ} \mathrm{C}$ or further extended incubation at $37^{\circ} \mathrm{C}$. The rate of decay in the photon correlation function was analyzed according to a cumulant method, and the corresponding diameter was calculated using the Stokes-Einstein equation. Herein, the yielded ultimate siRNA construct of RGD-PEG-PLys(siRNA) was determined to possess intensity-based DLS diameter of $13.1 \mathrm{~nm}$ with unimodal distribution (PDI: 0.06).

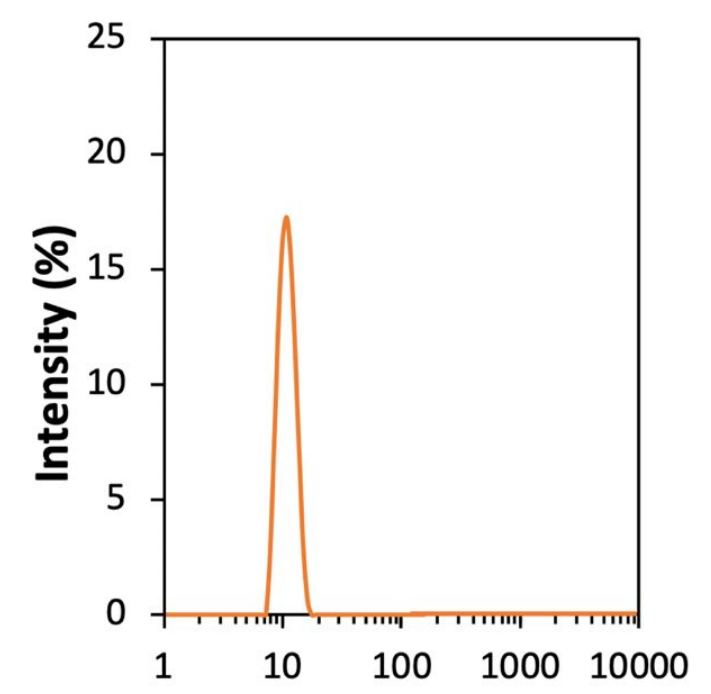

Figure S4 DLS result of the yielded RGD-PEG-PLys(siRNA).

\section{Insight into intracellular release of siRNA}

Cy5-labeled siRNA and Cy3-labeled siRNA were simultaneously conjugated to RGD-PEGPLys(thiol). Consequently, liberation of siRNA from RGD-PEG-PLys(thiol) derivatives can be estimated based on measurement of FRET of Cy3/Cy5. U87-Luc cells were seeded onto 6-well culture plates $(50,000$ cells/well) with $2,000 \mu$ of DMEM containing $10 \%$ FBS and $1 \%$ antibiotics (penicillin and streptomycin) and incubated in a humidified atmosphere 
supplemented with $5 \% \mathrm{CO}_{2}$ at $37{ }^{\circ} \mathrm{C}$. After $24 \mathrm{~h}$ incubation, the medium was replaced with fresh medium. The proposed RGD-PEG-PLys(siRNA) was added to U87-Luc cells for $1 \mathrm{~h}$ incubation on top of an ice bath. The medium was removed and the cells were rinsed 3 time with PBS (with the aim of synchronizing the cell internalization process), followed by continuous incubation at $37^{\circ} \mathrm{C}$. The cell nuclei were further stained with Hoechst 333342 (Dojindo Laboratories, Kumamoto, Japan). The FRET between Cy3 and Cy5 was quantified based on INCELL Analyzer (GE Healthcare Life Sciences, Boston, MA).

\section{Cellular uptake}

U87-Luc cells were seeded onto 6 -well culture plates $(50,000$ cells/well) with $2,000 \mu \mathrm{l}$ of DMEM containing 10\% FBS and 1\% antibiotics (penicillin and streptomycin) and incubated in a humidified atmosphere supplemented with $5 \% \mathrm{CO}_{2}$ at $37^{\circ} \mathrm{C}$. After $24 \mathrm{~h}$ incubation, the medium was replaced with fresh medium. The cells were treated with siRNA formulation solutions ( $1 \mu \mathrm{g}$ of Cy5-labeled siRNA/well) and followed by incubation for another $24 \mathrm{~h}$. The medium was discarded, cells were then washed three times with ice-cold PBS to remove extracellular fluorescence, and cells were detached by trypsin-EDTA treatment. The trypsinized cells were harvested from the cell culture plate and resuspended in $1 \mathrm{ml}$ ice-cold PBS. After filtering the cells through a nylon mesh, the cells were analyzed by a BD ${ }^{\text {tw }}$ LSR II flow cytometer equipped with FACS-Diva ${ }^{\text {Tw }}$ software (BD Biosciences, Franklin Lakes, NJ) to measure the fluorescence intensity of internalized pDNA. The obtained data were expressed as the mean fluorescence intensity from three independent samples $(n=3)$.

\section{Cytotoxicity}

U87-Luc cells were plated onto 24 -well culture dishes (20,000 cells/well) in $400 \mu$ l DMEM containing $10 \%$ FBS and $1 \%$ antibiotics (penicillin and streptomycin) and incubated in a humidified atmosphere with $5 \% \mathrm{CO}_{2}$ at $37{ }^{\circ} \mathrm{C}$. After $24 \mathrm{~h}$ of incubation, the medium was replaced with $400 \mu \mathrm{l}$ of fresh medium, followed by the addition of siRNA formulation solutions. After $24 \mathrm{~h}$ incubation, the medium was replaced with fresh medium, followed by another $24 \mathrm{~h}$ of incubation. The cells were washed three times with ice-cold PBS, followed by the addition of $200 \mu \mathrm{l}$ of fresh medium. Cell viability was assessed on the basis of 2-(2- 
methoxy-4-nitrophenyl)-3-(4-nitrophenyl)-5-(2,4-disulfophenyl)-2H-tetrazolium

(WST-8) reduction to WST-8 formazan by the dehydrogenase activity of viable cells using the Cell Counting Kit-8 (CCK-8) (Dojindo, Kumamoto, Japan) according to manufacturer's instructions. In brief, $20 \mu$ l of the CCK-8 reagent was added to each well and allowed to develop orangecolored WST-8 formazan for $2 \mathrm{~h}$. The UV absorbance of WST-8 formazan in each well was quantified at $450 \mathrm{~nm}$ using a microplate reader (Model 680, Bio-Rad, UK). The cell toxicity was expressed as the percentage of cell viability normalized against control cells treated with 10 mM HEPES $(\mathrm{pH} 7.4)(n=4)$.

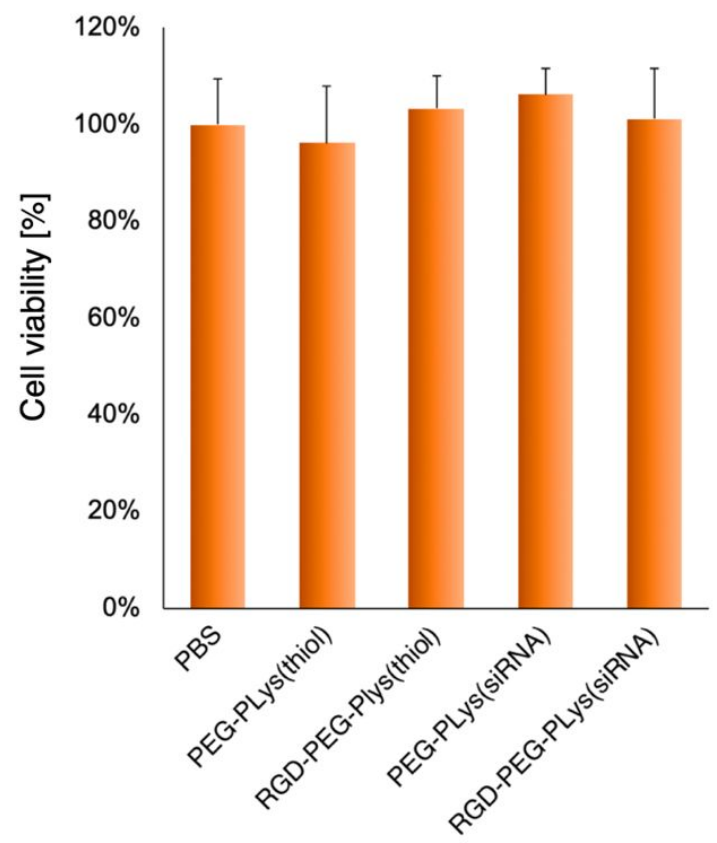

Figure S5 Cell viabilities of U87-Luc cells in presence of diverse samples $(0.1 \mathrm{mg} / \mathrm{mL})$.

\section{Gene knockdown efficiency}

U87-Luc cells were seeded onto 24 -well culture plates (20,000 cells/well) with $400 \mu$ l of DMEM containing 10\% FBS and 1\% antibiotics (penicillin and streptomycin) and incubated for $24 \mathrm{~h}$ in a humidified atmosphere supplemented with $5 \% \mathrm{CO}_{2}$ at $37^{\circ} \mathrm{C}$. After exchanging the medium with a fresh one, varied concentrated siRNA formulation solutions was added to each well. After $24 \mathrm{~h}$ incubation, the medium was exchanged with $400 \mu \mathrm{l}$ of fresh medium, followed by another $24 \mathrm{~h}$ incubation. The cells were washed three times with $400 \mu \mathrm{l}$ of ice-cold PBS and lysed by $150 \mu \mathrm{l}$ of cell culture lysis buffer at $37^{\circ} \mathrm{C}$ for $15 \mathrm{~min}$. Immediately, $20 \mu \mathrm{l}$ of the cell lysate was transferred to a 96-well luminometry plate, followed by the addition of $100 \mu \mathrm{l}$ of 
Luciferase Assay Reagent (Promega, Madison, WI) to each well, and allowed to react for 15 min. The Luc level was then measured for $10 \mathrm{~s}$ from the photoluminescence intensity using Mithras LB 940 (Berthold Technologies, Bad Wildbad, Germany). The amount of total protein in the cell lysate was quantified using the Micro BCA Protein Assay Kit (Pierce, Rockford, IL), and the obtained Luc activity was normalized against the corresponding amount of total protein in the cell lysates. The data were expressed as relative light units (RLU) per mg of protein (RLU/mg protein) $(n=6)$.

\section{Statistical Analysis.}

The $p$ values were determined by the Student's t-test using a two-tailed distribution and twosample un-equal variance with the T. Test function of Microsoft Excel. The $p$ values of less than 0.05 were considered as statistically significant.

\section{Reference:}

(S1) Dirisala, A., Uchida, S., Tockary T. A., Yoshinaga, N., Li, J., Osawa, S., Gorantla, S., Fukushima, K., Osada, K., and Kataoka, K. (2019) Precise tuning of disulfide crosslinking in mRNA polyplex micelles for optimizing extracellular and intracellular nuclease tolerability. J. Drug Target. 27, 670-680.

(S2) Dirisala, A., Osada, K., Chen, Q., Tockary, T. A., Machitani, K., Osawa, S., Liu, X., Ishii, T., Miyata, K., Oba, M., et al. (2014) Optimized rod length of polyplex micelles for maximizing transfection efficiency and their performance in systemic gene therapy against stroma-rich pancreatic tumors. Biomaterials 35, 5359-5368. 